\title{
Protocatechuic Acid from Pear Inhibits Melanogenesis in Melanoma Cells
}

\author{
Xuan T. Truong ${ }^{1}$, Seo-Hee Park ${ }^{1}$, Yu-Geon Lee ${ }^{1}$, Hang Yeon Jeong ${ }^{2}$, Jae-Hak Moon ${ }^{2}$ \\ and Tae-Il Jeon 1 ,* \\ 1 Department of Animal Science, Chonnam National University, Gwangju 61186, Korea; \\ trongxuan.vp@gmail.com (X.T.T.); seohee55@jnu.ac.kr (S.-H.P.); ugun2@naver.com (Y.-G.L.) \\ 2 Department of Food Science and Technology, BK21 Plus Program, Chonnam National University, \\ Gwangju 61186, Korea; wjdgkddus@naver.com (H.Y.J.); nutrmoon@chonnam.ac.kr (J.-H.M.) \\ * Correspondence: tjeon@jnu.ac.kr; Tel.: +82-62-530-2127; Fax: +82-62-530-2129
}

Received: 5 July 2017; Accepted: 17 August 2017; Published: 21 August 2017

\begin{abstract}
Despite the critical role of melanin in the protection of skin against UV radiation, excess production of melanin can lead to hyperpigmentation and skin cancer. Pear fruits are often used in traditional medicine for the treatment of melasma; therefore, we investigated the effects of pear extract (PE) and its component, protocatechuic acid (PCA), on melanogenesis in mouse melanoma cells. We found that PE and PCA significantly suppressed melanin content and cellular tyrosinase activity through a decrease in the expression of melanogenic enzymes and microphthalmia-associated transcription factor (Mitf) in $\alpha$-melanocyte stimulating hormone-stimulated mouse melanoma cells. Moreover, PCA decreased cyclic adenosine monophosphate (cAMP) levels and cAMP-responsive element-binding protein phosphorylation, which downregulated Mitf promoter activation and subsequently mediated the inhibition of melanogenesis. These results suggested that pear may be an effective skin lightening agent that targets either a tyrosinase activity or a melanogenic pathway.
\end{abstract}

Keywords: hyperpigmentation; melanogenesis; melanoma; pear; protocatechuic acid

\section{Introduction}

Melanin pigment, the primary determinant of skin and hair color in mammals, also protects the skin from injuries related to UV irradiation [1]. However, excessive cutaneousmelanin deposition, which may occur through increases in the number of melanocytes or melanin synthesis, can lead to hyperpigmentation disorders such as melasma, actinic and senile lentigines, and post-inflammatory hyperpigmentation $[2,3]$.

Melanin is synthesized through the complex process of melanogenesis, which occurs within vesicles called melanosomes in melanocytes and is mediated by melanocyte-specific enzymes, such as tyrosinase and tyrosinase-related proteins (TRPs) [4]. Tyrosinase is the rate-limiting enzyme that catalyzes the hydroxylation of tyrosine into dihydroxyphenylalanine (DOPA), followed by the subsequent oxidation of DOPA into dopaquinone. TRP1 and TRP2 are also present in the melanosome and play a critical role in melanin biosynthesis [5].

Melanogenesis is mainly stimulated by $\alpha$-melanocyte stimulating hormone ( $\alpha$-MSH), which is produced from proopiomelanocortin in response to UV irradiation [6]. $\alpha$-MSH activates the cyclic adenosine monophosphate (cAMP)-protein kinase A (PKA) pathway through the melanocortin receptor 1 (MC1R), the activation of which upregulates the transcription of microphthalmia-associated transcription factor (MITF), the master regulator in the transcription of genes encoding melanogenic enzymes [4]. Alterations in MITF expression are highly associated with abnormal skin and hair pigmentation [7]. Indeed, it has been reported that the downregulation of MITF expression by tea catechins was responsible for a reduction of melanin synthesis in mouse and human 
melanoma [8]. Thus, MITF is an attractive molecular target for the potential treatment or prevention of hyperpigmentation disorders.

Asian pear (mostly Pyrus spp.) belongs to the Rosaceae family and is one of the most widely consumed fruits in Eastern Asia. It is not only used as a fruit but also as a traditional medicine against cough, diuresis, and melasma [9]. Many investigations have revealed that the presence of polyphenol-rich foods in the diet may be related to a lower risk of hyperpigmentation [3] and various phenolic compounds from pear fruits have been identified in our previous studies [10-12]. Therefore, in this study, we investigated the anti-melanogenic effects of pear fruit extract and evaluated the depigmentation mechanisms of the extract and its constituent protocatechuic acid (PCA) in mouse melanoma cells.

\section{Results and Discussion}

\subsection{Pear Extract (PE) Inhibits Melanin Synthesis in B16F10 Cells}

To determine the effects of pear extract (PE) on cytotoxicity, B16F10 cells were treated with a range of $\mathrm{PE}$ concentrations, from 0.05 to $1 \mathrm{mg} / \mathrm{mL}$, for $72 \mathrm{~h}$ and the cell viability was measured using the 3-(4,5-dimethylthiazol-2-yl)-2,5-diphenyltetrazolium bromide (MTT) assay. PE exerted no significant cytotoxicity up to $0.5 \mathrm{mg} / \mathrm{mL}$ (Figure 1a). Next, to assess the effect of PE on melanin production in B16F10 cells, cells were stimulated with $\alpha$-MSH for $72 \mathrm{~h}$ in the presence or absence of PE. $\alpha$-MSH induced an increase in melanin content, but PE treatment decreased the $\alpha$-MSH-induced melanin increase in a dose-dependent manner, as shown in Figure 1b. The inhibitory effect was superior to that of $2 \mathrm{mM}$ arbutin, which was used as positive control. Several depigmenting agents decrease melanin synthesis in melanocytes through the inhibition of tyrosinase activity [13], and we have previously identified arbutin, which was extracted from PE, as a tyrosinase inhibitor [14]; therefore, the inhibitory activity of PE towards tyrosinase, the key enzyme of melanogenesis, was also evaluated. Although $\alpha$-MSH-induced melanin production was dramatically inhibited by $0.5 \mathrm{mg} / \mathrm{mL}$ PE (Figure $1 b$ ), the extract showed only moderate inhibitory effects on tyrosinase activity in comparison with arbutin (Figure 1c), which suggested that mechanisms other than the direct inhibition of tyrosinase activity may be responsible for the anti-melanogenic effect of PE.

(a)

Cell viability

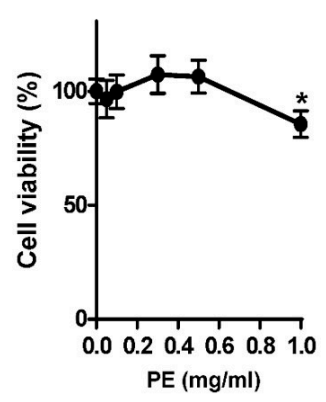

(b) Melanin content

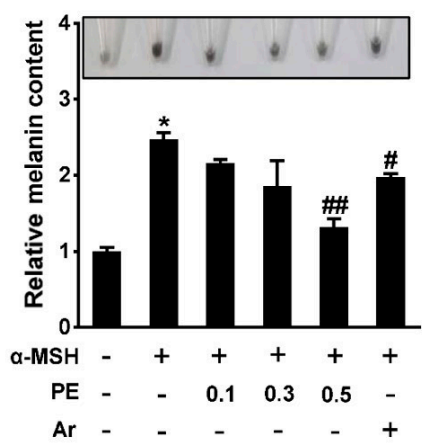

(c) Mushroom tyrosinase

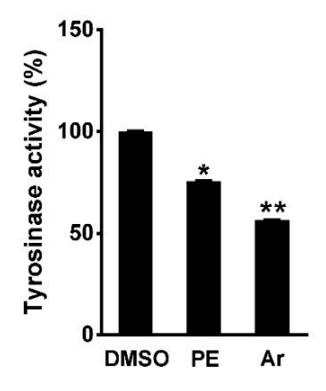

Figure 1. Effects of pear extract (PE) on melanogenesis in mouse melanoma cells. (a) B16F10 cells were treated with various concentrations of PE for $72 \mathrm{~h}$. The cell viability was measured by 3-(4,5-dimethylthiazol-2-yl)-2,5-diphenyltetrazolium bromide (MTT) assay. ${ }^{*} p<0.05$ vs. control dimethyl sulfoxide (DMSO); (b) Cells were exposed to $1 \mu \mathrm{M} \alpha$-melanocyte stimulating hormone $(\alpha-\mathrm{MSH})$ in presence or absence of PE $(\mathrm{mg} / \mathrm{mL})$ or $2 \mathrm{mM}$ arbutin $(\mathrm{Ar})$ for $72 \mathrm{~h}$. Cell pellet images were taken using a digital camera and melanin contents were measured with synthetic melanin as standard. ${ }^{*} p<0.05$ vs. control; ${ }^{\#} p<0.05$ vs. $\alpha-\mathrm{MSH}$; ${ }^{\# \#} p<0.01$ vs. $\alpha-\mathrm{MSH}$; (c) Mushroom tyrosinase activity in the absence or presence of PE $(0.5 \mathrm{mg} / \mathrm{mL})$ or arbutin $(2 \mathrm{mM}) .{ }^{*} p<0.05 \mathrm{vs}$. DMSO; ${ }^{* *} p<0.01$ vs. DMSO. 


\subsection{PE Inhibits Melanogenic Gene Expression}

To determine the mechanism of action of PE on melanogenesis, we examined the expression levels of key melanogenic genes such as Mitf, tyrosinase (Tyr), Trp1, and Trp2 in B16F10 cells. As shown in Figure 2, $\alpha$-MSH significantly increased both the mRNA and protein levels of these genes, whereas PE treatment decreased the $\alpha$-MSH-induced MITF, TYR, TRP1, and TRP2 levels in a dose-dependent manner. MITF, a basic helix-loop-helix leucine zipper transcription factor, is involved in the pigmentation, proliferation, and survival of melanocytes. The regulation of tyrosinase gene expression by MITF is a critical event in melanogenesis [15]. Therefore, our results suggested that PE suppressed melanogenesis via the MITF-mediated decrease of tyrosinase and TRPs expression.

(a)
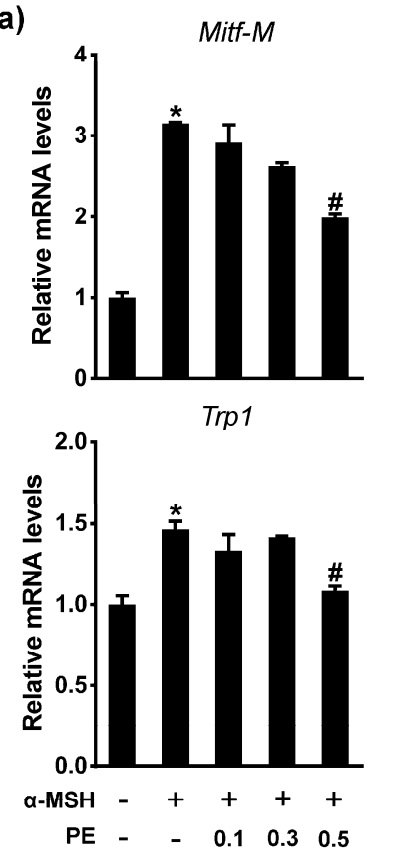
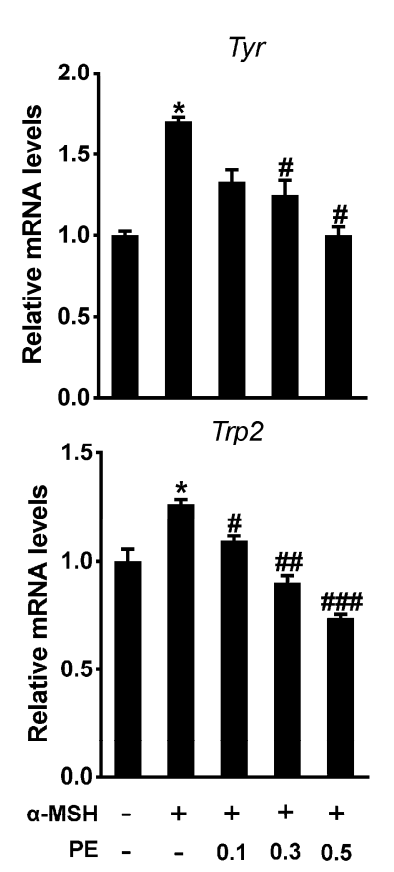

(b)

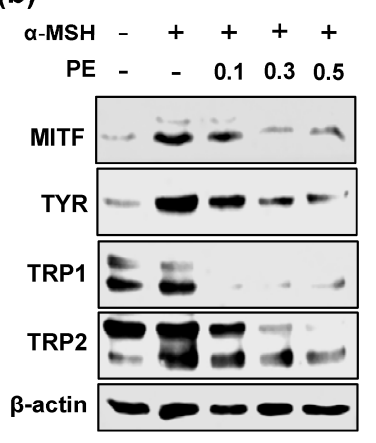

Figure 2. Effects of PE on expression of melanogenic genes. B16F10 cells were exposed to $\alpha$-MSH in presence or absence of PE $(\mathrm{mg} / \mathrm{mL})$ for $24 \mathrm{~h}$. (a) mRNA levels for Mitf-M, Tyr, Trp1, and Trp2 were analyzed by RT-qPCR. * $p<0.05$ vs. control; ${ }^{\#} p<0.05$ vs. $\alpha$-MSH; ${ }^{\# \#} p<0.01$ vs. $\alpha$-MSH; ${ }^{\# \# \# ~} p<0.001$ vs. $\alpha$-MSH. Data are mean \pm SEM; $n=3$; (b) Cell lysates were analyzed for microphthalmia-associated transcription factor (MITF), tyrosinase (TYR), tyrosinase-related protein 1 (TRP1), and tyrosinase-related protein 2 (TRP2) protein levels by immunoblotting.

\subsection{Protocatechuic Acid Inhibits Melanogenesis}

Because arbutin is a well-known tyrosinase inhibitor and was reported as a major constituent of PE in our previous paper [10], it may be responsible for the inhibitory effects of PE on melanogenesis (Figure 1c). However, numerous studies [16-18] have shown that arbutin did not affect the mRNA expression of MITF; this was consistently found in our observations (Figure S1), which suggested that other components may be involved in the effects of PE. A recent study reported that PCA inhibited melanin production in B16F10 cells, but a mechanism was not determined [19] and we have previously identified PCA as one of the major constituents of PE [10]. In present study, we quantified the contents of arbutin and PCA by high-performance liquid chromatography (HPLC) analysis (Figure S2). Arbutin and PCA contents (mg/100 g fresh weight) in immature pear fruit were $197.33 \pm 6.56$ and $0.21 \pm 0.01$, respectively.

Therefore, we investigated whether PCA was the active constituent responsible for the antimelanogenic effect of PE in B16F10 cells. PCA markedly suppressed the $\alpha$-MSH-induced increase in melanin content and cellular tyrosinase activity without affecting cell viability (Figure 3a-d). However, 
unlike arbutin (Figure 1c), PCA had no direct inhibitory effect on the enzymatic activity of tyrosinase (Figure 3e). There is no doubt that the specific inhibition of tyrosinase activity would be an effective therapy for the reduction of hyperpigmentation, but the use of many tyrosinase inhibitors such as hydroquinone, arbutin, and kojic acid, as depigmenting agents, cause severe adverse effects including skin irritation, genotoxicity, or pigmented contact dermatitis [13]. Our results showed that PCA was not toxic to B16F10 cells and exerted a potent anti-melanogenic effect (Figure 3); therefore, PCA could be a potential non-toxic alternative for hyperpigmentation treatment.

(a)<smiles>O=C(O)c1ccc(O)c(O)c1</smiles>

Protocatechuic acid (PCA) (b)

Cell viability

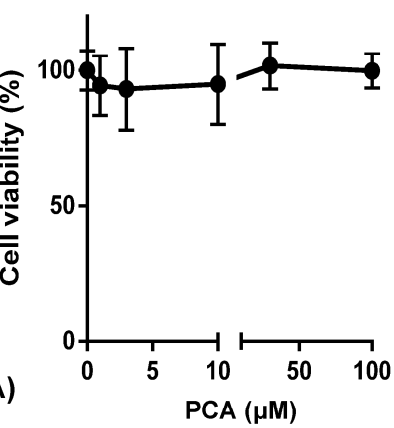

(c) Melanin contents

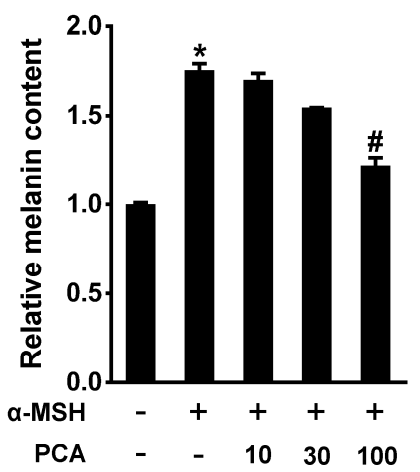

(d) Tyrosinase activity (cell lysates)

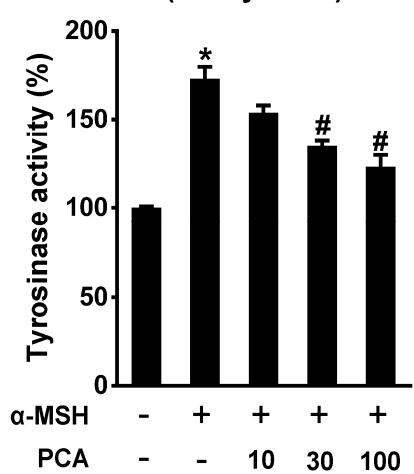

(e) Mushroom tyrosinase

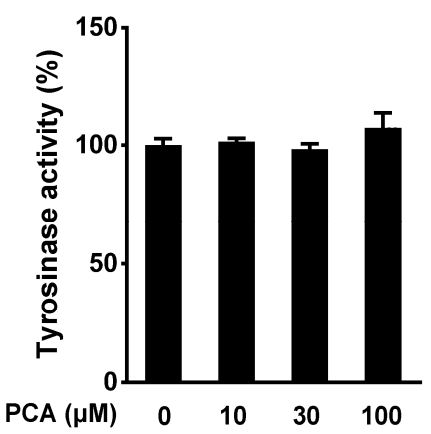

Figure 3. Effects of protocatechuic acid (PCA) on melanin synthesis and tyrosinase activity. (a) Structure of PCA; (b) B16F10 cells were treated with various concentrations of PCA for $72 \mathrm{~h}$. The cell viability was measured by MTT assay; (c) Cells were exposed to $1 \mu \mathrm{M} \alpha-\mathrm{MSH}$ in presence or absence of PCA $(\mu \mathrm{M})$ for $72 \mathrm{~h}$. Melanin contents were measured with synthetic melanin as standard. ${ }^{*} p<0.05 \mathrm{vs}$. control; ${ }^{\#} p<0.05$ vs. $\alpha$-MSH; (d) Cells were exposed to $1 \mu \mathrm{M} \alpha-\mathrm{MSH}$ in presence or absence of PCA $(\mu \mathrm{M})$ for $24 \mathrm{~h}$. Cellular tyrosinase activity. ${ }^{*} p<0.05$ vs. control; ${ }^{*} p<0.05$ vs. $\alpha-\mathrm{MSH}$; (e) Mushroom tyrosinase activity in a cell free system. Data are mean $\pm \mathrm{SEM} ; n=3$.

\subsection{Protocatechuic Acid (PCA) Inhibits Melanogenic Genes through the Downregulation of Microphthalmia-Associated Transcription Factor (MITF) Transcription}

Next, we examined whether PCA inhibited the expression of melanogenic genes. Similar to the effects produced by PE, PCA treatment also significantly decreased the mRNA and protein levels of the $\alpha$-MSH-induced melanogenic genes, including Mitf, Tyr, Trp1, and Trp2, in B16F10 cells (Figure 4a,b). Moreover, PE and PCA inhibit melanin contents and mRNA and protein expression of MITF and TYR in human melanoma SK-MEL-28 cells (Figure S3). The MITF gene has multiple promoters and at least nine promoter-exon units direct the transcription initiation of specific MITF isoforms by alternative splicing [2]. The MITF-M promoter that is located nearest to the common downstream exons is selectively expressed in melanocytes and is targeted by several transcriptional factors including paired 
box gene 3, cAMP-responsive element-binding protein (CREB), SRY (sex-determining region Y)-box 10 (SOX10), lymphoid enhancer-binding factor 1, and MITF itself [7].

Because both PE and PCA significantly inhibited the expression of Mitf mRNA, we examined whether PCA suppressed Mitf expression through transcriptional regulation. To test this, B16F10 cells were transiently transfected with luciferase reporter plasmids containing wild type MITF-M promoter (melanocyte-specific isoform) sequences. $\alpha$-MSH upregulated MITF promoter activity, whereas PCA treatment significantly suppressed the effect of $\alpha-\mathrm{MSH}$ in a dose-dependent manner (Figure 4c). Although the activation of the MITF promoter is regulated by several transcription factors, it is classically activated by a conserved cAMP-responsive element (CRE) in response to $\alpha$-MSH signaling [20]. As shown in Figure 4c, the deletion of the CRE in the MITF promoter (mtCRE) markedly reduced the stimulation of activity in response to $\alpha-\mathrm{MSH}$ and completely blocked the inhibitory effect of PCA, which indicated that the CRE motif was essential for the PCA downregulation of MITF transcription.
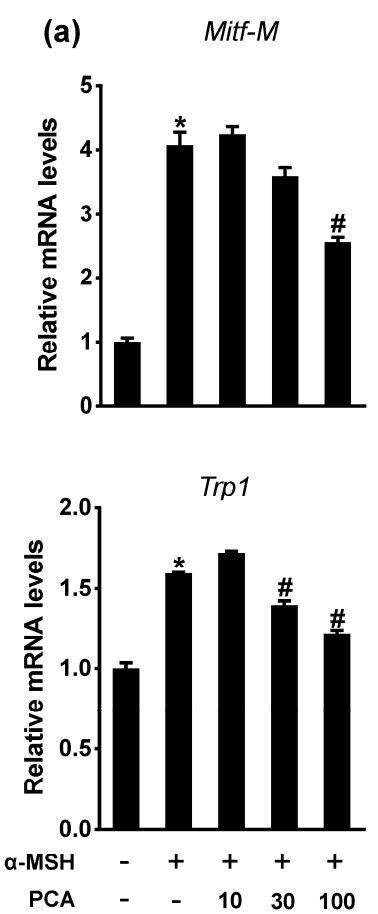
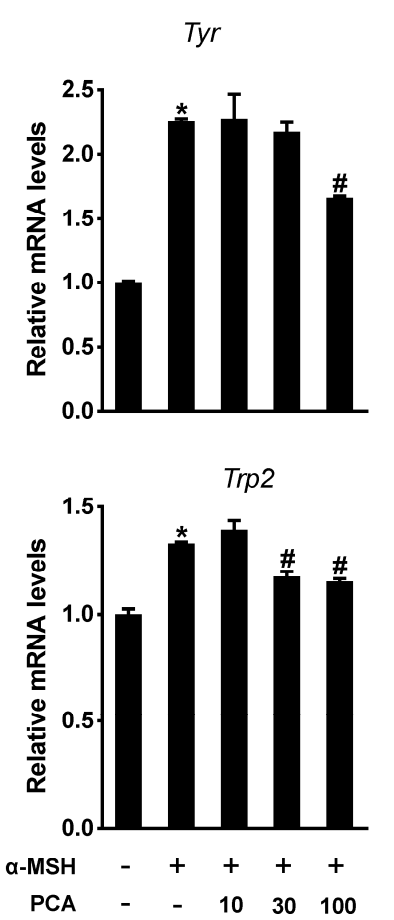

(b) a-MSH -++++

PCA - $\quad 1030100$

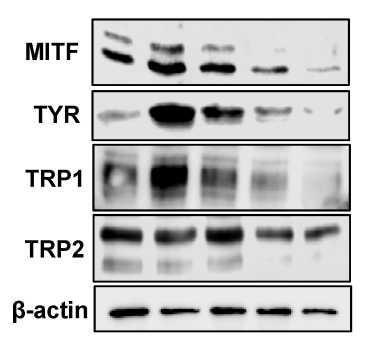

(c) Mitf-M promoter $-1.1 \mathrm{~Kb}$

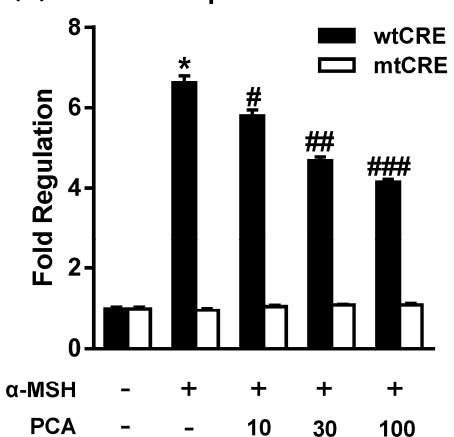

Figure 4. Effects of PCA on expression of melanogenic genes and activation of MITF promoter. B16F10 cells were exposed to $\alpha$-MSH in presence or absence of PCA $(\mu \mathrm{M})$ for $24 \mathrm{~h}$. (a) mRNA levels for Mitf-M, Tyr, Trp1, and Trp2 were analyzed by RT-qPCR. ${ }^{*} p<0.05$ vs. control; ${ }^{*} p<0.05$ vs. $\alpha$-MSH. Data are mean \pm SEM; $n=3$; (b) Cell lysates were analyzed for MITF, TYR, TRP1, and TRP2 protein levels by immunoblotting; (c) Reporter assays were performed using mouse MITF-M promoter construct. Cells were transfected with wild type (wt) cAMP-responsive element (CRE) or mtCRE luciferase reporters for $24 \mathrm{~h}$ before treatment with PCA $(\mu \mathrm{M})$ and/or $\alpha-\mathrm{MSH}$ for $24 \mathrm{~h} .{ }^{*} p<0.05$ vs. control; ${ }^{\#} p<0.05$ vs. $\alpha$-MSH; ${ }^{\# \#} p<0.01$ vs. $\alpha$-MSH; ${ }^{\# \# \#} p<0.005$ vs. $\alpha$-MSH. Data are mean $\pm \mathrm{SEM} ; n=3$.

\subsection{PCA Downregulates Cyclic Adenosine Monophosphate (cAMP)/cAMP-Responsive Element Binding Protein (CREB) Signaling Pathway}

The binding of $\alpha$-MSH to MC1R in melanocytes induces the activation of adenylyl cyclase (AC), which is followed by an increase in cAMP levels. The cAMP pathway leads to phosphorylation of the CREB transcription factor, which in turn stimulates MITF-M promoter activation [4]. Thus, to identify the signaling pathways that are regulated by PCA in melanogenesis, we determined whether PCA regulated CREB activation in response to $\alpha-\mathrm{MSH}$. The treatment of B16F10 cells with $\alpha$-MSH increased 
CREB phosphorylation, but either PCA or PE completely abrogated it (Figure 5a). $\alpha$-MSH and cAMP signaling also induced expression of the transcriptional coactivator PPAR- $\gamma$ coactivator (PGC)- $1 \alpha$ in melanocytes, thereby enhancing the transcriptional activation of MITF by CREB and SOX10, which subsequently mediated the induction of melanogenesis [21]. As shown in Figure 5b, $\alpha$-MSH-induced $P g c-1 \alpha$ expression was also significantly decreased by PCA. Because this effect could be mediated by cAMP, we measured the levels of cAMP in B16F10 cells. PCA treatment significantly decreased intracellular cAMP levels in $\alpha$-MSH-stimulated conditions (Figure $5 \mathrm{c}$ ), which suggested that the reduction in CAMP accumulation by PCA resulted in the deactivation of CREB and PGC- $1 \alpha$.

(a)

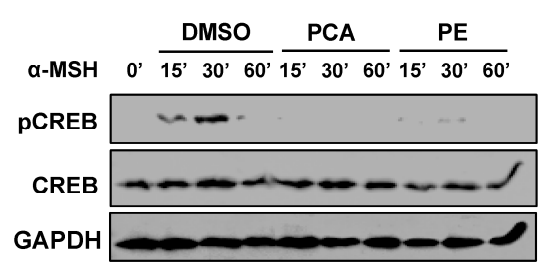

(b)

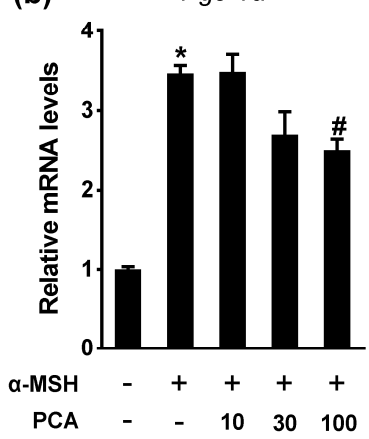

(c) CAMP

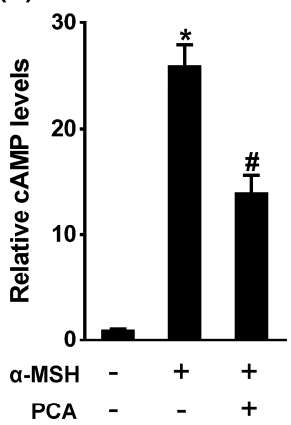

(d)

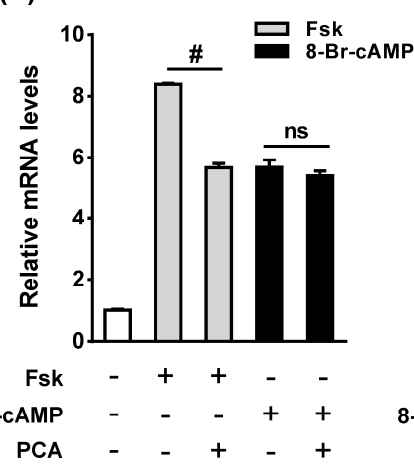

Pgc-1 $\alpha$

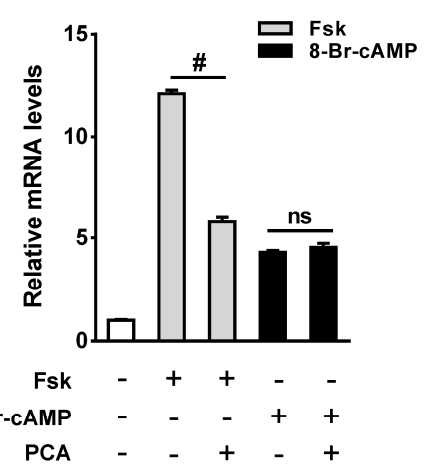

(e)

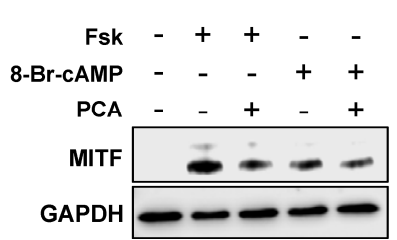

Figure 5. Effects of PCA on CREB phosphorylation and intracellular cAMP level. B16F10 cells were pretreated with $100 \mu \mathrm{M}$ PCA for $24 \mathrm{~h}$ prior to $1 \mu \mathrm{M} \alpha$-MSH treatment for indicated time. (a) Cell lysates were analyzed for PCREB, CREB, and GAPDH protein levels by immunoblotting; (b) mRNA levels for Pgc- $1 \alpha$ were analyzed by RT-qPCR. ${ }^{*} p<0.05$ vs. control; ${ }^{\#} p<0.05$ vs. $\alpha$-MSH; (c) Cells were pretreated with $100 \mu \mathrm{M}$ PCA for $24 \mathrm{~h}$, and then exposed to $1 \mu \mathrm{M} \alpha$-MSH for $30 \mathrm{~min}$. Intracellular cAMP concentration was measured by immunoassay as described in Materials and methods. ${ }^{*} p<0.05$ vs. control; ${ }^{\#} p<0.05$ vs. $\alpha$-MSH; (d) Cells were exposed to $20 \mu \mathrm{M}$ forskolin (Fsk) or $100 \mu \mathrm{M}$ 8-Br-cAMP in presence or absence of PCA $(100 \mu \mathrm{M})$ for $24 \mathrm{~h}$. mRNA levels for Mitf-M and Pgc-1 $\alpha .{ }^{\#} p<0.05 \mathrm{vs.} \mathrm{Fsk;}$ ns, not significant. Data are mean \pm SEM; $n=3$; (e) Protein level for MITF.

To further elucidate the mechanism by which PCA suppressed the $\alpha$-MSH-induced expression of Mitf and Pgc-1 $\alpha$, we utilized forskolin and 8-Br-cAMP, which mimic the action of $\alpha$-MSH in melanogenesis by bypassing MC1R and G proteins. Forskolin is a direct activator of AC and 8-Br-cAMP is a cell-permeable analog of cAMP. Interestingly, PCA decreased the forskolin-induced expression of Mitf and Pgc-1 $\alpha$, but did not affect the stimulation by 8-Br-cAMP. This indicated that PCA may specifically target AC rather than the downstream effectors of cAMP (Figure 5d,e). Collectively, these results suggested that PCA suppressed the $\alpha$-MSH-induced MITF transcription via the downregulation of cAMP-mediated CREB activation.

Our results indicated that PE suppressed $\alpha$-MSH-stimulated melanin synthesis and this inhibitory effect was correlated with either a decrease in the enzymatic activity of tyrosinase, probably owing 
to the presence of arbutin, or a decrease in MITF expression via the reduction of cAMP production, probably owing to presence of PCA (Figure 6).

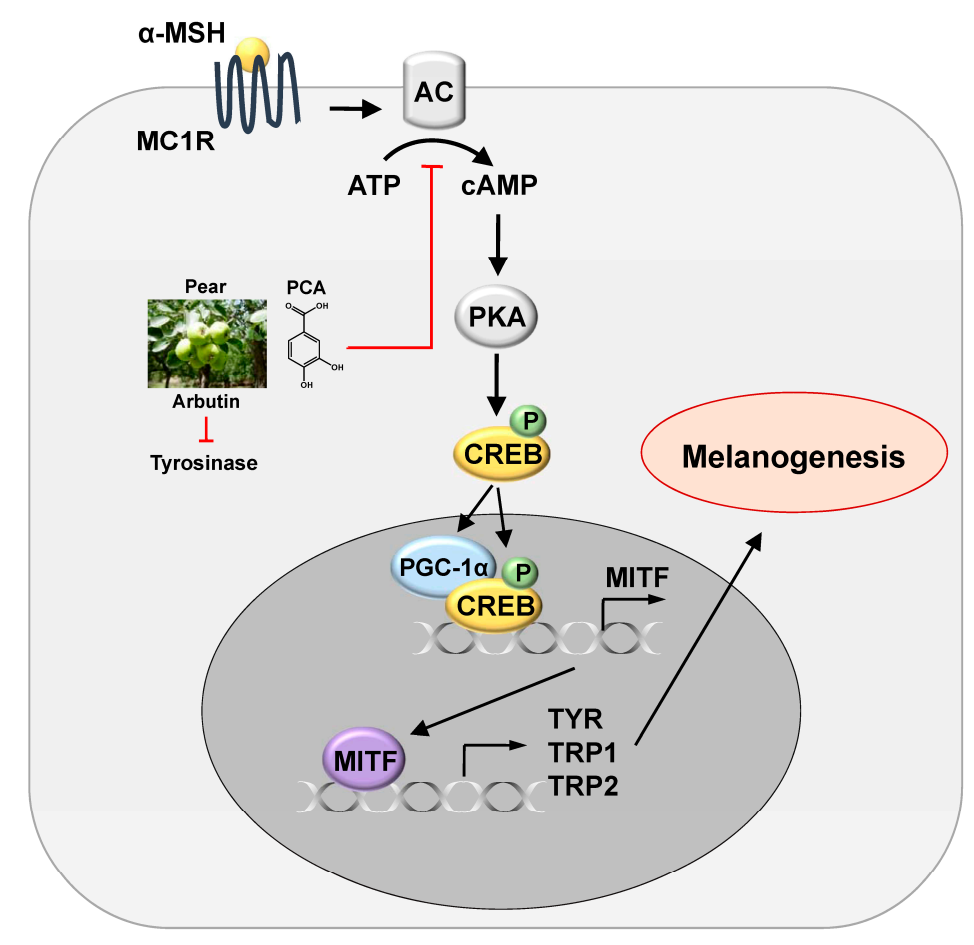

Figure 6. A proposed mechanism for inhibitory effect of PE and its components (PCA and arbutin) on melanogenesis. Arrows indicate positive regulation while T-bars denote inhibitory effects.

\section{Materials and Methods}

\subsection{Materials and Cell Culture}

Pear (Pyrus pyrifolia Nakai cv. Chuhwangbae) was cultivated in Naju and its immature fruit was collected in May 2015 after 35 days of florescence. The samples were certified by Wol-Soo Kim (Laboratory of Pomology, College of Agriculture and Life Science, Chonnam National University, South Korea). Arbutin (A4256), PCA (37580), $\alpha$-MSH, melanin, forskolin, 8-bromoadenosine 3',5'-cyclic monophosphate (8-Br-cAMP), and 3-(4,5-dimethylthiazol-2-yl)-2,5-diphenyltetrazolium bromide (MTT) were purchased from Sigma-Aldrich Chemical Co. (St. Louis, MO, USA). B16F10 and SK-MEL-28 cells were purchased from American Type Culture Collection (ATCC, Manassas, VA, USA) and maintained in Dulbecco's modified Eagle's medium supplemented with 10\% heat-inactivated fetal bovine serum and $1 \%$ antibiotics (100 U/mL penicillin/streptomycin) in an atmosphere of $5 \%$ $\mathrm{CO}_{2}$ at $37^{\circ} \mathrm{C}$. All cell culture reagents were obtained from Gibco BRL (Grand Island, NY, USA).

\subsection{Sample Preparation}

Immature pear fruit ( $1 \mathrm{~kg}$, fresh weight) was homogenized with $60 \%$ ethanol $(4 \mathrm{~L})$ by using a homogenizer (T50 digital ULTRA-TURRAX, IKA, Staufen, Germany). The homogenate was kept at $25^{\circ} \mathrm{C}$ for $24 \mathrm{~h}$ and filtered under vacuum through no. 2 filter paper (Whatman, Maidstone, UK). The filtrates were concentrated, lyophilized, and stored at $-20{ }^{\circ} \mathrm{C}$ until used.

\subsection{Determination of Arbutin and PCA Contents in Immature Pear Fruit}

Immature pear fruit extract (1 $\mathrm{g}$ fresh weight equivalent) was dissolved in $50 \%$ methanol $(1 \mathrm{~mL})$ and filtered through a $0.45 \mu \mathrm{m}$ Millipore membrane filter. The dissolved solution was subjected to Octadecyl-silica (ODS)-HPLC analysis. Arbutin and PCA were separated on an ODS column 
(UG120, $4.6 \mathrm{~mm}$ internal diameter (ID) $\times 250 \mathrm{~mm}, 5 \mu \mathrm{m}$, Shiseido, Tokyo, Japan). The mobile phase was composed of $\mathrm{H}_{2} \mathrm{O}$ /acetic acid $(98: 2, v / v$, eluent $\mathrm{A})$ and $\mathrm{MeOH} / \mathrm{H}_{2} \mathrm{O}(60: 40, v / v$, eluent B). The gradient program used was as follows: started at $100 \% \mathrm{~A}$ and increased to $100 \% \mathrm{~B}$ linearly over $45 \mathrm{~min}$. The column temperature was maintained at $40{ }^{\circ} \mathrm{C}$ and the flow rate was $1 \mathrm{~mL} / \mathrm{min}$. Arbutin and PCA were monitored at 280 and $254 \mathrm{~nm}$, respectively, using a photodiode array detector (SPD-M20D; Shimadzu, Kyoto, Japan). Arbutin and PCA contents in each sample were quantified by the chromatographic peak area of external standards. The calibration curves were plotted in the concentration range of $0.01-10 \mu \mathrm{g}$.

\subsection{Cell Viability}

The cells were seeded in 96-well plates, treated with various concentrations of PE or PCA for $72 \mathrm{~h}$, and then incubated with MTT for $2 \mathrm{~h}$. After the incubation, the cells were thoroughly washed with phosphate-buffered saline (PBS) and the insoluble formazan product was dissolved in dimethyl sulfoxide (DMSO). The absorbance of each well was measured at $560 \mathrm{~nm}$ by using a microplate reader (Biotek, Winooski, VT, USA). The absorbance of $0.1 \%$ DMSO-treated control cells was considered to represent $100 \%$ viability.

\subsection{Determination of Melanin Content}

The cells were treated with $\alpha$-MSH $(1 \mu \mathrm{M})$ in the presence or absence of PE, PCA, or arbutin (positive control) for $72 \mathrm{~h}$, trypsinized and centrifuged at $1000 \times \mathrm{g}$ for $5 \mathrm{~min}$ at $4{ }^{\circ} \mathrm{C}$. The cell pellets were photographed and then solubilized in $1 \mathrm{~N} \mathrm{NaOH}$ containing $10 \%$ DMSO at $80^{\circ} \mathrm{C}$ for $1 \mathrm{~h}$. The melanin content was calculated by the comparison of the absorbance at $405 \mathrm{~nm}$ with those of a standard curve of synthetic melanin.

\subsection{Measurement of Tyrosinase Activity}

To measure the tyrosinase activity in a cell free system, $1250 \mathrm{U} / \mathrm{mL}$ of mushroom tyrosinase solution $(20 \mu \mathrm{L})$ was added to a mixture of $50 \mathrm{mM}$ sodium phosphate buffer, $\mathrm{pH} 6.8(100 \mu \mathrm{L})$, the desired sample $(5 \mu \mathrm{L})$, and $5 \mathrm{mM}$ L-tyrosine $(125 \mu \mathrm{L})$. After incubation for $5 \mathrm{~min}$ at $25^{\circ} \mathrm{C}$, the production of dopachrome was determined by monitoring the change in absorbance at $475 \mathrm{~nm}$ every $20 \mathrm{~s}$ for $30 \mathrm{~min}$.

To measure cellular tyrosinase activity, the cells were first treated with PCA for $24 \mathrm{~h}$ and then $\alpha$-MSH $(1 \mu \mathrm{M})$ was added. After incubation for $24 \mathrm{~h}$, the cells were washed with PBS and centrifuged at $1000 \times g$ for $5 \mathrm{~min}$ at $4{ }^{\circ} \mathrm{C}$. The cell pellets were resuspended in radioimmunoprecipitation assay (RIPA) buffer and centrifuged at $20,000 \times g$ for $20 \mathrm{~min}$ at $4{ }^{\circ} \mathrm{C}$. The supernatant was used as a crude enzyme solution. The crude enzyme solution ( $20 \mu \mathrm{L}$; equivalent to $100 \mu \mathrm{g}$ protein) was added to a mixture of $50 \mathrm{mM}$ sodium phosphate buffer, $\mathrm{pH} 6.8(100 \mu \mathrm{L})$ and $5 \mathrm{mM}$ L-tyrosine $(30 \mu \mathrm{L})$. After incubation for $3 \mathrm{~h}$ at $37^{\circ} \mathrm{C}$, the absorbance of the solution was measured at $475 \mathrm{~nm}$.

\subsection{RNA Analysis}

Total RNA was isolated using TRIzol ${ }^{\mathrm{TM}}$ (Invitrogen, Carlsbad, CA, USA), cDNA was synthesized using ReverTra Ace ${ }^{\circledR}$ qPCR RT kit (Toyobo, Osaka, Japan), and quantitative PCR was performed using a Mx3000P qPCR System (Agilent Technologies, Santa Clara, CA, USA). The primer sequences used in this study are shown in Table S1. mRNA levels were normalized to the expression of mouse ribosomal protein, Large, P0 (Rplp0), and the data were calculated by the comparative threshold cycle method.

\subsection{Immunoblotting}

The cells were washed with PBS and centrifuged at $1000 \times g$ for 5 min at $4{ }^{\circ} \mathrm{C}$. The obtained pellets were resuspended in RIPA buffer with protease and proteasome inhibitors, incubated on ice for $20 \mathrm{~min}$, sonicated, and centrifuged at $20,000 \times \mathrm{g}$ for $20 \mathrm{~min}$ at $4{ }^{\circ} \mathrm{C}$. The supernatants were separated using $8 \%$ or $10 \%$ SDS-PAGE and then transferred to nitrocellulose membranes. The membranes were 
incubated overnight at $4{ }^{\circ} \mathrm{C}$ with primary antibodies against MITF, GAPDH (Thermo Fisher Scientific, Rockford, IL, USA), tyrosinase, TRP1, TRP2, $\beta$-actin (Santa Cruz Biotechnology, Santa Cruz, CA, USA), cAMP-responsive element binding protein (CREB), or pCREB (Cell Signaling Technology, Danvers, MA, USA), which was followed by incubation with the appropriate secondary antibodies (Thermo Fisher Scientific, Rockford, IL, USA). The blots were developed by using the EZ-Western Lumi Femto ${ }^{\mathrm{TM}}$ western blot detection kit (Daeil Lab Service, Seoul, Korea).

\subsection{Luciferase Reporter Assay}

The mouse MITF-M promoter construct ( -1143 to +48 , wtCRE) was amplified via PCR using mouse genomic DNA as template, and cloned into the pGL3-basic firefly luciferase reporter vector (Promega, Madison, WI, USA). The mtCRE was constructed by deleting the CRE motif $(-153 /-146$, 5'-TGACGTCA-3') by using the site-directed mutagenesis kit (Agilent Technologies, Santa Clara, CA, USA). All constructs were verified via DNA sequencing. The cells were seeded in 24 -well plates and transfected for $24 \mathrm{~h}$ with pGL3-Mitf-M (wtCRE or mtCRE) luciferase reporter, using Lipofectamine ${ }^{\circledR}$ 2000 reagent (Invitrogen, Carlsbad, CA, USA), before treatment with $\alpha$-MSH and/or PCA for a further $24 \mathrm{~h}$. The cells were harvested and assayed using the Nano-Glo ${ }^{\circledR}$ Dual-Luciferase ${ }^{\circledR}$ Reporter Assay System (Promega, Madison, WI, USA). The pNL1.1 luciferase vector (Promega, Madison, WI, USA) was used as a normalization control.

\subsection{0. cAMP Determination}

The cells were pretreated with PCA for $24 \mathrm{~h}$, exposed to $\alpha$-MSH for $30 \mathrm{~min}$, washed in PBS, and lysed in $0.1 \mathrm{M} \mathrm{HCl}$. After centrifugation, the cAMP in the supernatant was measured by a cAMP assay kit (BioVision, Milpitas, CA, USA).

\subsection{Statistical Analysis}

All experiments were performed a minimum of three times. The data were presented as the mean \pm SEM. The differences between the means of the individual groups were assessed using Student's $t$-test or one-way analysis of variance (ANOVA); differences were considered significant at $p<0.05$. The statistical software package Prism 6.0 (GraphPad Software, La Jolla, CA, USA) was used for these analyses.

\section{Conclusions}

Pear fruit and its constituent PCA effectively inhibit cellular tyrosinase activity and expression through CAMP/CREB/MITF-mediated mechanism, which contributes to reduction in $\alpha$-MSH-stimulated melanogenesis in mouse and human melanoma. These effects of pear may help to prevent or treat hyperpigmentation.

Supplementary Materials: Supplementary materials can be found at www.mdpi.com/1422-0067/18/8/1809/s1. Acknowledgments: This work was supported by High Value-added Food Technology Development Program through Korea Institute of Planning and Evaluation for Technology in Food, Agriculture, Forestry and Fisheries (IPET) funded by Ministry of Agriculture, Food and Rural Affairs (MAFRA) (315069-3).

Author Contributions: Xuan T. Truong performed most experiments and prepared manuscript. Yu-Geon Lee contributed to promoter cloning and mutation. Seo-Hee Park, Hang Yeon Jeong and Jae-Hak Moon contributed to sample preparation, HPLC analysis, and the discussion section, respectively. Tae-Il Jeon designed the study and revised the manuscript. All authors read and reviewed the manuscript.

Conflicts of Interest: The authors declare no conflict of interest.

\section{References}

1. Jablonski, N.G. The evolution of human skin and skin color. Annu. Rev. Anthropol. 2004, 33, 585-623. [CrossRef] 
2. Slominski, A.; Tobin, D.J.; Shibahara, S.; Wortsman, J. Melanin pigmentation in mammalian skin and its hormonal regulation. Physiol. Rev. 2004, 84, 1155-1228. [CrossRef] [PubMed]

3. Leyden, J.J.; Shergill, B.; Micali, G.; Downie, J.; Wallo, W. Natural options for the management of hyperpigmentation. J. Eur. Acad. Dermatol. Venereol. 2011, 25, 1140-1145. [CrossRef] [PubMed]

4. D'Mello, S.A.; Finlay, G.J.; Baguley, B.C.; Askarian-Amiri, M.E. Signaling pathways in melanogenesis. Int. J. Mol. Sci. 2016, 17, 1144. [CrossRef] [PubMed]

5. Solano, F.; Briganti, S.; Picardo, M.; Ghanem, G. Hypopigmenting agents: An updated review on biological, chemical and clinical aspects. Pigment Cell Res. 2006, 19, 550-571. [CrossRef] [PubMed]

6. Yamaguchi, Y.; Hearing, V.J. Physiological factors that regulate skin pigmentation. Biofactors 2009, 35, $193-199$. [CrossRef] [PubMed]

7. Levy, C.; Khaled, M.; Fisher, D.E. MITF: Master regulator of melanocyte development and melanoma oncogene. Trends Mol. Med. 2006, 12, 406-414. [CrossRef] [PubMed]

8. Sato, K.; Toriyama, M. Depigmenting effect of catechins. Molecules 2009, 14, 4425-4432. [CrossRef] [PubMed]

9. Cui, T.; Nakamura, K.; Ma, L.; Li, J.Z.; Kayahara, H. Analyses of arbutin and chlorogenic acid, the major phenolic constituents in Oriental pear. J. Agric. Food Chem. 2005, 53, 3882-3887. [CrossRef] [PubMed]

10. Lee, K.H.; Cho, J.Y.; Lee, H.J.; Park, K.Y.; Ma, Y.K.; Lee, S.H.; Cho, J.A.; Kim, W.S.; Park, K.H.; Moon, J.H. Isolation and identification of phenolic compounds from an Asian pear (Pyrus pyrifolia Nakai) fruit peel. Food Sci. Biotechnol. 2011, 20, 1539-1545. [CrossRef]

11. Lee, K.H.; Cho, J.Y.; Lee, H.J.; Ma, Y.K.; Kwon, J.; Park, S.H.; Lee, S.H.; Cho, J.A.; Kim, W.S.; Park, K.H.; et al. Hydroxycinnamoylmalic Acids and Their Methyl Esters from Pear (Pyrus pyrifolia Nakai) Fruit Peel. J. Agric. Food Chem. 2011, 59, 10124-10128. [CrossRef] [PubMed]

12. Lee, Y.G.; Cho, J.Y.; Kim, C.M.; Lee, S.H.; Kim, W.S.; Jeon, T.I.; Park, K.H.; Moon, J.H. Coumaroyl quinic acid derivatives and flavonoids from immature pear (Pyrus pyrifolia Nakai) fruit. Food Sci. Biotechnol. 2013, 22, 803-810. [CrossRef]

13. Pillaiyar, T.; Manickam, M.; Namasivayam, V. Skin whitening agents: Medicinal chemistry perspective of tyrosinase inhibitors. J. Enzym. Inhib. Med. Chem. 2017, 32, 403-425. [CrossRef] [PubMed]

14. Cho, J.Y.; Park, K.Y.; Lee, K.H.; Lee, H.J.; Lee, S.H.; Cho, J.A.; Kim, W.S.; Shin, S.C.; Park, K.H.; Moon, J.H. Recovery of arbutin in high purity from fruit peels of pear (Pyrus pyrifolia Nakai). Food Sci. Biotechnol. 2011, 20, 801-807. [CrossRef]

15. Widlund, H.R.; Fisher, D.E. Microphthalamia-associated transcription factor: A critical regulator of pigment cell development and survival. Oncogene 2003, 22, 3035-3041. [CrossRef] [PubMed]

16. Lee, Y.S.; Kim, H.K.; Lee, K.J.; Jeon, H.W.; Cui, S.; Lee, Y.M.; Moon, B.J.; Kim, Y.H.; Lee, Y.S. Inhibitory effect of glyceollin isolated from soybean against melanogenesis in B16 melanoma cells. BMB Rep. 2010, 43, 461-467. [CrossRef] [PubMed]

17. Kim, E.S.; Jo, Y.K.; Park, S.J.; Chang, H.; Shin, J.H.; Choi, E.S.; Kim, J.B.; Seok, S.H.; Kim, J.S.; Oh, J.S.; et al. ARP101 inhibits $\alpha$-MSH-stimulated melanogenesis by regulation of autophagy in melanocytes. FEBS Lett. 2013, 587, 3955-3960. [CrossRef] [PubMed]

18. Kim, S.E.; Lee, C.M.; Kim, Y.C. Anti-melanogenic effect of oenothera laciniata methanol extract in melan-a cells. Toxicol Res. 2017, 33, 55-62. [CrossRef] [PubMed]

19. Chou, T.H.; Ding, H.Y.; Lin, R.J.; Liang, J.Y.; Liang, C.H. Inhibition of melanogenesis and oxidation by protocatechuic acid from Origanum vulgare (oregano). J. Nat. Prod. 2010, 73, 1767-1774. [CrossRef] [PubMed]

20. Bertolotto, C.; Abbe, P.; Hemesath, T.J.; Bille, K.; Fisher, D.E.; Ortonne, J.P.; Ballotti, R. Microphthalmia gene product as a signal transducer in cAMP-induced differentiation of melanocytes. J. Cell Biol. 1998, 142, 827-835. [CrossRef] [PubMed]

21. Shoag, J.; Haq, R.; Zhang, M.; Liu, L.; Rowe, G.C.; Jiang, A.; Koulisis, N.; Farrel, C.; Amos, C.I.; Wei, Q.; et al. PGC-1 coactivators regulate MITF and the tanning response. Mol. Cell 2013, 49, 145-157. [CrossRef] [PubMed]

(C) 2017 by the authors. Licensee MDPI, Basel, Switzerland. This article is an open access article distributed under the terms and conditions of the Creative Commons Attribution (CC BY) license (http:/ / creativecommons.org/licenses/by/4.0/). 